\title{
Co-Use of Cannabis with Commonly Used Licit and Illicit Drugs
}

\author{
Aleksandar Maksimovic ${ }^{1}$, Helen Heacock ${ }^{2}{ }_{\text {iste-pi }}^{2}$ \\ ${ }^{1}$ Lead Author, B. Tech Student, School of Health Sciences, British Columbia Institute of \\ Technology, 3700 Willingdon Ave, Burnaby, BC V5G 3H2 \\ 2Supervisor, School of Health Sciences, British Columbia Institute of Technology, 3700 \\ Willingdon Ave, Burnaby, BC V5G 3H2
}

\begin{abstract}
Background: Following the recent legalization of medical cannabis in Canada, and many other countries around the world, people are turning to this drug for both medical and recreational reasons. Naturally, as human's age, many rely on medication to maintain a better quality of life. Surveys show that, once legal, there will be an increase in cannabis consumption. Many adverse health reactions may occur by concurrently taking cannabis and other medications.

Methods: A survey was distributed in-person throughout Vancouver targeting people who do not consume cannabis. The same survey was distributed in Vancouver, but to people coming out of dispensaries, targeting people who do consume cannabis. The survey consisted of seven knowledge questions asking about possible adverse drug interactions occurring between cannabis and commonly used licit and illicit drugs. A chi-square analysis was used to compare knowledge of users and non-users of cannabis.

Results: Both users and non-users seemed to be most knowledgeable on the interaction between cannabis and alcohol; 39 out of 57 users $(68 \%)$ and 23 out of 30 non-users $(77 \%)$ gave the correct response. As for all the other interactions, neither group was very knowledgeable. The distribution of questions that were answered incorrectly seemed evenly spread between the two groups. The knowledge between users and non-users were significantly different when participants were asked on the possible adverse reactions between cannabis and opioid drugs $(p=0.005)$, and cannabis and sedative drugs $(p=0.002)$. In these cases, cannabis users were more knowledgeable about cannabis interactions than non-users.

Conclusion: This study indicates that the general public is not very knowledgeable on the possible adverse reactions that may come about as a result of mixing cannabis and other commonly used licit and illicit drugs. Actions should be taken to provide the public with tools that will aid them in making the right decision when thinking about concurrently using cannabis and other licit and/or illicit drugs.
\end{abstract}

Keywords: Cannabis, Prescriptions, Drugs, Licit Drugs, Illicit Drugs, Drug Interactions, Adverse Interaction, Public Health, Environmental Health, Public Health

\section{Introduction}

Medical marijuana has been legalized in many parts of the world and as of October 2018, some forms of marijuana are also now legalized in Canada. Prior to its legalization, a survey showed that

approximately 18 percent of Canadian adults consumed cannabis in 2017 (Statista, 2018). Adding to this, 13 percent of Canadians said 
they would likely try cannabis after legalization and four percent said they would very likely do so (Evans, 2015). Many people, however, live their day-to-day life using some type of licit drugs, and as they get older, they tend to depend more on these drugs to achieve a better quality of life. In addition to this, people also take illicit drugs for reasons such as addiction, mental health issues, or recreationally. Given this information, this literature review will investigate the positive, negative, or neutral health effects that may occur due to co-use of cannabis and commonly used licit and illicit drugs. The licit drugs of interest will include alcohol, blood thinner drugs such as Warfarin and Heparin, blood pressure drugs, opioid drugs such as oxycodone and morphine, and lastly, sedative drugs such as Ativan and Valium. The illicit drugs of interest will include cocaine and heroin. These two illicit drugs were chosen specifically because they are commonly used and because cocaine is an "upper" and heroin is a "downer."

\section{Literature Review}

\section{Co-Use of Cannabis and Alcohol}

Mixing alcohol virtually with any drug is not a good idea due to the many adverse reactions it poses. Interestingly, couse of cannabis and alcohol is generally a popular combination amongst teenagers. In fact, this is one of the most frequently detected drug combinations in car accidents.

To shed light on this topic, a study showed the results from 32 adults ingesting placebo or low-dose alcohol, followed by inhaling $500 \mathrm{mg}$ of placebo, low-dose or high-dose THC from vaporized cannabis 10 minutes later (Hartman et al., 2015). Vaporization of cannabis was chosen because it is an effective THC delivery route. Measurements of THC and 11-OH-
THC in the blood were taken. The results showed that the participants who had concurrently taken cannabis and alcohol had significantly higher doses of THC and 11$\mathrm{OH}-\mathrm{THC}$, the main psychoactive compounds in cannabis, in their blood (Schwilke et al., 2009). It is evident that these values correlate with increased impairment from the co-use of cannabis and alcohol and should therefore lead to new drugged-driving legislation to be enforced in the near future.

\section{Co-Use of Cannabis and Blood Thinners Drugs (Examples: Warfarin, Heparin)}

Even though cannabis may give you the "munchies", it is actually found that it slows down your metabolism. This may increase the effect of blood thinning medications such as Warfarin and Heparin (Royal Queen Seeds, 2017). A recent study done on the interaction between warfarin and cannabidiol (CBD) supported these claims. Even though there are novel anticoagulants emerging frequently, Warfarin remains to be the most commonly used anticoagulant worldwide. Warfarin has two stereoisomers; S-warfarin and Rwarfarin. They are metabolized by two specific isoforms of the CYP450 hepatic enzyme complex. (Bristol-Myers-Squibb, 2011). Consequently, the metabolism of CBD is also done by the CYP450 enzyme. Ironically, the same isoforms involved in the metabolism of Warfarin are also involved in the metabolism of CBD.

Drugs like Warfarin require frequent monitoring due to the high specificity of dosing requirements among individuals. Monitoring yields an international normalized ratio (INR), which is required to maintain normal anticoagulant effects on blood. This ratio is a standard measurement of time it takes for blood to clot (INR Test Explained, 2017). In a study by Grayson et 
al. (2017), it was found that drugs, like CBD, compete as substrates for the Warfarin cytochromes, or inhibit their activity, and lead to adverse health effects. These health effects involve the increase of warfarin plasma concentrations and INR, potentially increasing the risk of bleeding. In addition, CBD has demonstrated to act as a potent competitive inhibitor of all of its own CYP enzymes, therefore also further impairing the degradation of Warfarin. This combination will definitely result in increased INR values (Grayson et al., 2017). The co-use of cannabis and blood thinning medications should be avoided until further research is done and this information should be implemented into a medical tool or guide that warns users about these adverse effects.

\section{Co-Use of Cannabis and Blood Pressure Drugs}

In $2017,17.8 \%(5,396,700)$ of Canadians aged 12 and older reported being diagnosed with high blood pressure (Statistics Canada, 2017). A recent study detected an association of recent cannabis use and increased systolic blood pressure, and high pulse blood pressure (Alshaarawy \& Elbaz, 2016). In the same study, no associations were detected between cannabis use and diastolic blood pressure levels, and hypertension or prehypertension. In addition, no association was detected between lifetime history of cannabis use and blood pressure levels.

Although both systolic and diastolic blood pressure levels correlate significantly with cardiovascular morbidity and mortality, recent studies have suggested that systolic blood pressure is more strongly correlated than diastolic blood pressure (Williams et al., 2008). Additionally, increased pulse pressure may be a strong predictor of cardiovascular disease (Millar \& Lever,
2000). Another study has shown a strong association between increased systolic blood pressure, increased pulse pressure, increased arterial stiffness and the prevalence of cardiovascular disease detection (Izzo, Levy, \& Black, 2000).

For most of these cases $(65 \%)$, Canadians aged 20 to 79 are aware they have hypertension and are treating it with medication. Given this information, when cannabis is used, it not only activates the bodies CB1 receptor but also the CB2 receptor as well (Kaplan, 2018). The cannabinoid receptors type I and II are found in tissues around the heart and blood vessels. The activation of $\mathrm{CB} 1$, and to a lesser extent $\mathrm{CB} 2$, receptors cause the blood vessels to dilate, lowering blood pressure, therefore causing the heart to work extra hard to adequately pump blood through the body. This can put dangerous levels of stress on the heart that increases risk for heart attacks (Pacher, Bátkai, \& Kunos, 2005). For these reasons, the co-use of cannabis and blood pressure medication should be avoided and this information should be implemented into a medical tool or guide that warns users about these adverse effects.

\section{Co-Use of Cannabis and Opioid Drugs (Examples: Percocets, Oxycodone, Hydromorphone, Morphine)}

The Canadian Drug Summary states that $13 \%$ of the Canadians use opioid pain relievers, and about $2 \%$ reported using them for non-medical purposes. The rate of hospitalization due to opioid poisoning has also been increasing, with an average of 13 hospitalizations per day in 2014 to 2015 and 2800 opioid-related deaths in Canada in 2016 (Centers for Disease Control and Prevention, 2017).

Canada clearly faces an opioid abuse problem, and with cannabis becoming legal, it is only appropriate to study the health 
effects of co-using cannabis and opioid drugs. A recent study showed that CBD combined with opioids produce a synergistic analgesia effect (Cooper et al., 2018). Healthy cannabis users were concurrently given oxycodone with smoked cannabis. A Cold-Pressor Test (CPT) was performed to assess for analgesia. This test involved the participant immersing their hand in cold water $\left(4^{\circ} \mathrm{C}\right)$ and recording a pain threshold (time to report pain) and pain tolerance (withdrawing the hand from the water). Using a higher dosage of oxycodone alone increased the pain threshold and tolerance. Using a lower dosage of oxycodone alone failed to elicit analgesia. However, when concurrently taking low dosage oxycodone with cannabis, it resulted in both pain threshold and tolerance increase (Cooper et al. 2018). Additionally, oxycodone was also found to not be associated with cannabis abuse, but the combination of lower dosage oxycodone and active cannabis produced a significant enough increase in oxycodone abuse.

These findings could support future research for therapeutic use of opioidcannabinoid combinations similar to the study done in Colorado by Livingston et al. (2017). This study showed that Colorado's legalization of recreational cannabis resulted in a 0.7 deaths per month reduction in opioid-related deaths (Livingston et al., 2017). Following legalization of cannabis and the release of related statistics, a study, similar to this, can be done for opioidrelated deaths in Canada, and hopefully, similar results will be found. Overall, the couse of cannabis and opioid medications could result in positive health effects, by users decreasing their dependence on opioid medications. This information should be implemented into a medical tool or guide to explain to users about these positive health effects.
Co-Use of Cannabis and Sedative Drugs

(Examples: Ativan, Valium, Codeine)

Sedative drugs exert an anesthetic effect on humans by binding to the GABA receptors. This causes a structural change to the receptors which, in turn, alters its activity. Unlike THC, which binds to the $\mathrm{CB} 1$ and $\mathrm{CB} 2$ receptors, $\mathrm{CBD}$ is shown to exert similar functions as sedative drugs (Oliveira, Johnstone, \& Chen, 2017).

A study showed that CBD are able exert changes in the GABA receptor activity, regulating the electrical currents that are sent out. This resulted in an observation seen in sedative drugs as well; no alteration to maximal GABA concentrations. The study suggested that CBD may be safe to use for treating the same human symptoms that sedative drugs treat (Bakas et al. 2017).

Sedative drugs, specifically benzodiazepines, form a substrate called 2AG. When 2-AG and CBD were concurrently examined, effects were still observed even though it lacked proteins over which benzodiazepines act. This suggests that 2-AG and CBD have different binding sites. Additionally, further research showed that $\mathrm{CBD}$ had a higher binding selectivity than 2-AG. (Oliveira, Johnstone, \& Chen, 2017). These results suggest that CBD is able to reduce symptoms of anxiety without the side effects of sedation or ataxia.

Based on this information, people who are taking sedatives and wish to stop taking pharmaceutical drugs could possibly use cannabis as an alternative, given that their doctor agrees. The co-use of cannabis and sedatives, and even more so cannabis use by itself, definitely exhibits beneficial health effects for the stated health issues. This information should be implemented into a medical tool or guide to explain to users about these positive health effects. 
Co-Use of Cannabis with Illicit Drug Cocaine

Cocaine and cannabis are two of the most recreationally used drugs across North America (World Drug Report, 2018). Cocaine is an illicit stimulant, also known as an "upper", that causes individuals to feel rushes of euphoria and energy (Royal Queen Seeds, 2017). Inevitably, it causes blood pressure levels to heighten, along with paranoia and heart rate (Foltin \& Fischman, 1990). Cannabis has the opposite effect, acting as a depressant, also known as a "downer" (Lindsay, Stotts, Green, Herin \& Schmitz, 2009). Although some may believe taking cannabis and cocaine can reduce the intensity of a cocaine high, it actually only feels that way. The effects of the cocaine are actually still affecting the body the same way (The Recovery Village, 2018). The opposing effects of these drugs can cause confusion in the body and create significant health problems as the true effects of cocaine are blunted, individuals may take more drugs. As dosages and frequency increase, the risk of imposing more severe complications increase, potentially leading to overdose (Degenhardt \& Hall, 2012).

Side effects of frequent co-use of cannabis and cocaine can be physical and psychological. Foltin, Fishcman, Pedroso, \& Pearlson's (1987) study tested a group of 7 adult males who were give a one gram cannabis cigarette $(0-2.7 \%$ delta $9-\mathrm{THC}$ $\mathrm{w} / \mathrm{w})$ to smoke and cocaine hydrochloride $(0-32 \mathrm{mg})$ was administered intravenously 13 minutes after the start of smoking the cannabis. Afterwards, the individuals were given a learning exercise and blood pressure and heart rate were measured. The study found that the co-use of cocaine and cannabis increased heart rate even more so than either of the drugs did on their own (Foltin et al., 1987).
In Lindsay et al.'s (2009) study, 1183 cocaine rehabilitation patients were assessed for cannabis use. The patients were subdivided into three groups and observed for 30 days. The three groups included were patients reporting no recent cannabis use, occasional concurrent cannabis use, and frequent concurrent cannabis use. In the individuals who reported concurrent use of cannabis and cocaine it was found that the level of cannabis use was positively related to length of time using cocaine, with an earlier onset and increased chances of becoming dependent (Lindsay et al., 2009). It was also found that cocaine-dependent individuals with frequent marijuana use were shown to have more severe impairment than individuals who only used marijuana frequently. Finally, individuals who were cocaine-dependent with frequent marijuana use were reported with more medical, legal, and psychiatric problems, including antisocial personality disorder (Lindsay et al., 2009). Marijuana and cocaine should not be co-used because they show an additive effect that may lead to many adverse health effects. This information should be implemented into a medical tool or guide that warns users about these adverse effects.

\section{Co-Use of Cannabis with Illicit Drug Heroin}

When discussing the co-use of heroin and marijuana, there is one term that describes both of these substances; "downers", drugs that affect the most basic processes occuring in our bodies needed to keep us alive. Their effects cause the slowing or inhibition of these processes therefore causing users to experience sedation, disinhibition of emotion and impulses, muscle relaxation, and drowsiness (George Mason University, 2012). In South Africa, there is a drug called nyaope, which is a mixture of cannabis and heroin. Because of its cheap cost, it has made its mark 
throughout the underdeveloped towns of South Africa, affecting mostly the vulnerable youth. In addition to the high unemployment rate, the negative consequences resulting from this drug are homelessness, begging, and petty crimes to feed the need for it.

In contrast to the negative effects of Nyaope, a study showed that when the two drugs are concurrently taken, cannabis may actually lower the craving for heroin. Scientists used an experimental rat model and observed the self-administration and drug-seeking behavior that it exhibited after receiving $5-20 \mathrm{mg} / \mathrm{kg}$ of CBD. The results showed that CBD constricted the heroinseeking behavior. Even after 24 hours and two weeks after administration, the same results were yielded (Ren et al., 2009).

Another study also looked at the effects of cannabis on patients undergoing methadone maintenance treatment (MMT). Researchers discovered that those who were taking cannabis during the stabilization phase of the treatment had a decrease in opiate withdrawal (Scavone et al., 2013). These findings clearly suggest that cannabis may be a potential treatment for heroin craving and relapse, and should be implemented into a medical tool or guide to explain to users about these positive health effects.

\section{Purpose of the Study}

Currently, the only government monitoring of cannabis related adverse reactions is done by having consumers report any occurances via an online government website. Additionally, health professionals, manufacaturers, and distributors must report any adverse reaction occurances that they are aware of (Statistics Canada, 2017). The purpose of this study is to discover any possible drug interactions that may occur when concurenntly using cannabis and commonly used licit and illicit drugs. Whether these interactions are positive, negative, or neutral, a survey will be conducted to determine how informed the public is, and whether action is needed to be taken towards creating an educational tool, such as warnage signs explaining common drug interactions with cannabis.

\section{Methods and Materials}

\section{Materials}

During this survey, data was collected in-person via an interview questionnaire. A personal vehicle was used to commute to various locations needed to conduct the research. Paper documents that were used include; surveys, consent forms, and cover letters. The participants were awarded with a BCIT pen, at the beginning, to complete the questionnaire. Additionally, they received a BCIT badge, upon completion of the questionnaire. The information gathered was recorded with a pen and uploaded to Microsoft Excel on a computer. This information was then fed into NCSS in order to perform chi-square analyses. This research paper was written on Microsoft Word.

\section{Standard methods}

The standard method used was an inperson interview. This research study aimed to compare the knowledge of cannabis users and non-users. Cannabis users were targeted by invitation upon leaving medical dispensaries and asked to participate in the study. Cannabis non-users were targeted at busy areas throughout the city including malls, Skytrain stations, and in front of Vancouver Art Gallery. Since the majority of the dispensaries are operating in Vancouver, BC, that is where both the users and non-users were interviewed (Google Maps, 2018). Even though this specific demographic was chosen, participants were 
not asked if they are currently living in this geographic region. Most people come from all over the lower mainland into Vancouver to purchase cannabis for several reasons. Reasons include greater quality of product, well-established dispensary franchises, and Amsterdam-café style lounges (Greater Vancouver Cannabis Dispensaries, 2018).

This study aimed to assess general knowledge of cannabis interactions with licit and illicit drugs. As such, only a few closedended questions were asked. They are easier to analyze statistically (Heacock, n.d.). The initial question asked whether or not the participant is over 19 (legal cannabis age) and therefore eligible to do this survey (Cannabis Control and Licensing Act, 2018). Next, the participants were asked whether or not they are a user of cannabis; because these are the two groups that were compared. Refer to appendix A for survey questions.

\section{Results}

Description of Data

The collected data is primary because it is collected and analyzed using a survey for the first time. This data is nominal dichotomous and multichotomous (Heacock, n.d.).

\section{Descriptive Statistics}

Due to the fact that there are already an extensive number of hypotheses involved with this project, some common descriptive factors were excluded from the survey (age, sex, residence, etc.) due to time constraints. However, some conclusions can be made on these various factors based on personal observation. A total of 87 individuals completed the survey. Of those 87, 57 were cannabis users and 30 were cannabis nonusers. The majority of participants were males, under the age of 30, living within the Greater Vancouver.
Both users and non-users seemed to be most knowledgeable on the interaction between cannabis and alcohol; 39 out of 57 users $(68 \%)$ and 23 out of 30 non-users $(77 \%)$ gave the correct response as seen in the bar graph in figure 1.

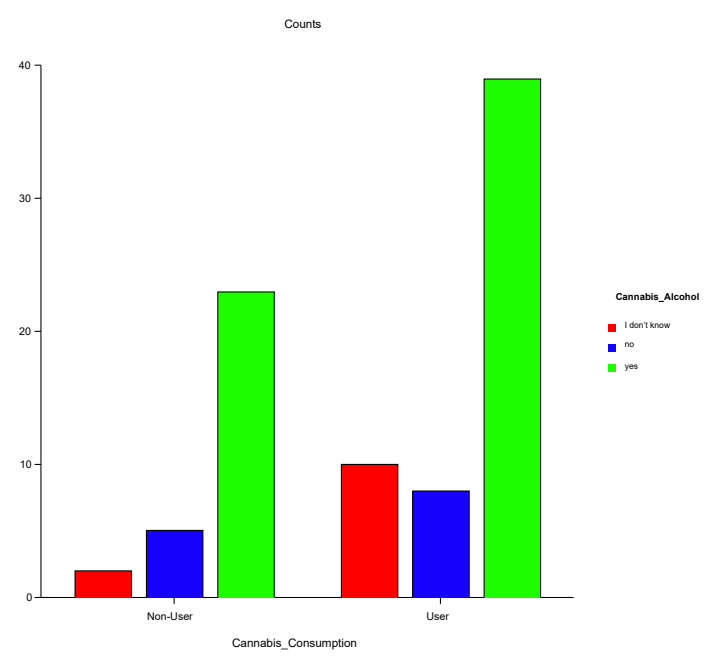

Figure 1. NCSS Chi-Square Bar Graph for Cannabis and Alcohol Interaction

As for all the other interactions, neither group seemed to be very knowledgeable. There seemed to be a fair number of respondents answering "I don't know" and also answering the wrong answer, presumably due to guessing. The non-users answered, "I don't know" more often than the users. The distribution of questions that were answered incorrectly seemed evenly spread between the two groups.

Hypotheses $\mathrm{H} 04$ and $\mathrm{H} 05$ were rejected and their respective alternative hypotheses were accepted; all the other null hypotheses were not rejected. For hypothesis $\mathrm{H} 04$, there is an association between cannabis usage and knowledge on the possible adverse reaction between cannabis and opioid drugs. 14 users and 4 non-users answered the correct response as seen in the bar graph in figure 2 . 


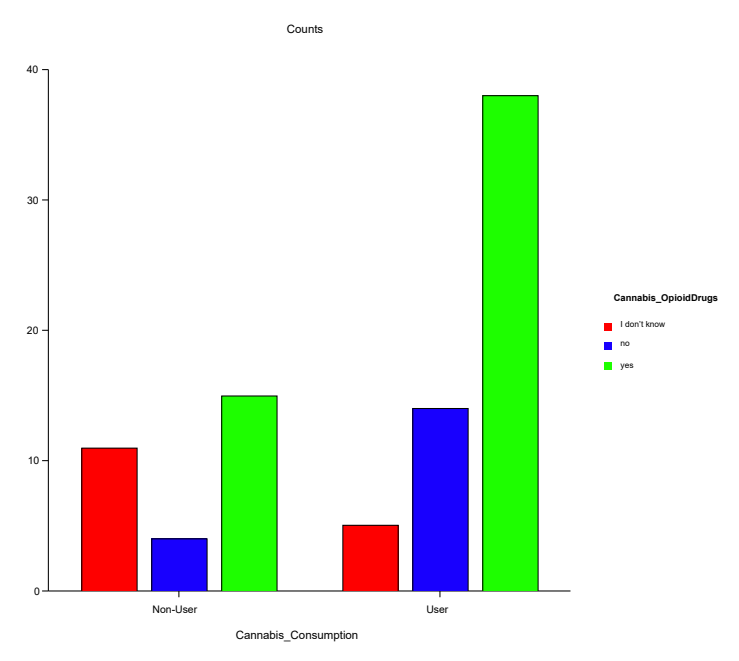

Figure 2. NCSS Chi-Square Bar Graph for Cannabis and Opioid Drug Interaction

That is a significant association in correct response; the users seem to be more knowledgeable. For hypothesis H05, there is an association between cannabis usage and knowledge on the possible adverse reaction between cannabis and sedative drugs. 14 users and 2 non-users answered the correct response as seen in the bar graph in figure 3.

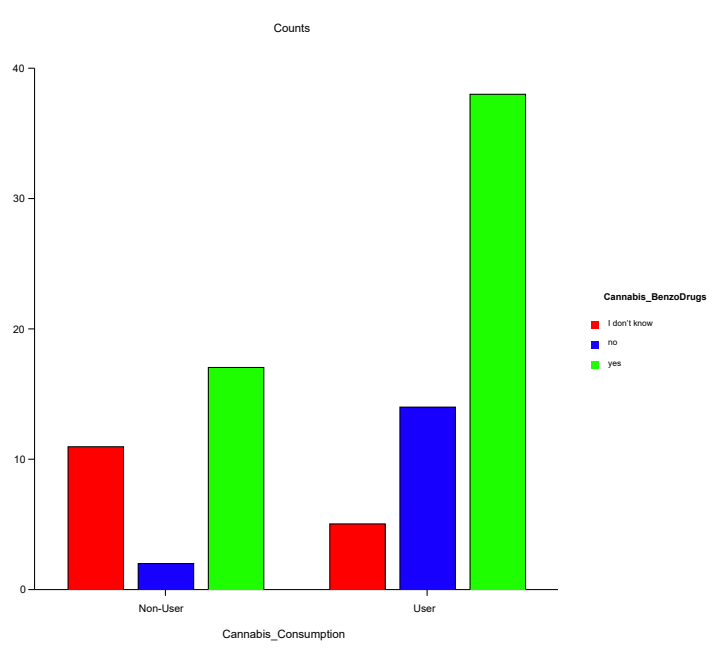

Figure 3. NCSS Chi-Square Bar Graph for Cannabis and Sedative Drug Interaction

That is a significant association in correct response; the users seem to be more educated.

\section{Results of Inferential Statistics}

\begin{tabular}{|l|l|l|}
\hline H0 and Ha & Results & Conclusion \\
\hline $\begin{array}{l}\text { H01: Cannabis usage and knowledge } \\
\text { on possible adverse cannabis-alcohol } \\
\text { interactions is independent. }\end{array}$ & $\mathrm{P}=0.37445$ & Do not reject H01. \\
$\begin{array}{l}\text { Ha1: Cannabis usage and knowledge } \\
\text { on possible adverse cannabis-alcohol } \\
\text { interactions is not independent. }\end{array}$ & $\begin{array}{l}\text { There is no association between } \\
\text { cannabis usage and knowledge on } \\
\text { cannabis-alcohol interactions. }\end{array}$ \\
\hline $\begin{array}{l}\text { H02: Cannabis usage and knowledge } \\
\text { on possible adverse cannabis-blood } \\
\text { thinner drug interactions is } \\
\text { independent. }\end{array}$ & $\mathrm{P}=0.41715$ & Do not reject H02. \\
$\begin{array}{l}\text { Ha2: Cannabis usage and knowledge } \\
\text { on possible adverse cannabis-blood } \\
\text { thinner drug interactions is not } \\
\text { independent. }\end{array}$ & $\begin{array}{l}\text { There is no association between } \\
\text { cannabis usage and knowledge on } \\
\text { cannabis-blood thinner drug } \\
\text { interactions. }\end{array}$ \\
\hline $\begin{array}{l}\text { H03: Cannabis usage and knowledge } \\
\text { on possible adverse cannabis-blood } \\
\text { pressure drug interactions is } \\
\text { independent. }\end{array}$ & $\mathrm{P}=0.19566$ & Do not reject H03. \\
\hline
\end{tabular}




\begin{tabular}{|c|c|c|}
\hline $\begin{array}{l}\text { Ha3: Cannabis usage and knowledge } \\
\text { on possible adverse cannabis-blood } \\
\text { pressure drug interactions is not } \\
\text { independent. }\end{array}$ & & $\begin{array}{l}\text { cannabis-blood pressure drug } \\
\text { interactions. }\end{array}$ \\
\hline $\begin{array}{l}\text { H04: Cannabis usage and knowledge } \\
\text { on possible adverse cannabis-opioid } \\
\text { drug interactions is independent. } \\
\text { Ha4: Cannabis usage and knowledge } \\
\text { on possible adverse cannabis-opioid } \\
\text { drug interactions is not independent. }\end{array}$ & $\mathrm{P}=0.00549$ & $\begin{array}{l}\text { Reject H04, and accept Ha4. } \\
\text { There is an association between } \\
\text { cannabis usage and knowledge on } \\
\text { cannabis-opioid drug interactions. The } \\
\text { correct answer is "no." } 14 \text { users said no } \\
\text { and } 4 \text { non-users said no. That is a } \\
\text { significant association in correct } \\
\text { responses. The users seem to be more } \\
\text { knowledgeable on this topic. }\end{array}$ \\
\hline $\begin{array}{l}\text { H05: Cannabis usage and knowledge } \\
\text { on possible adverse cannabis- } \\
\text { sedative drug interactions is } \\
\text { independent. } \\
\text { Ha5: Cannabis usage and knowledge } \\
\text { on possible adverse cannabis- } \\
\text { sedative drug interactions is not } \\
\text { independent. }\end{array}$ & $\mathrm{P}=0.00242$ & $\begin{array}{l}\text { Reject H05, and accept Ha5. } \\
\text { There is an association between } \\
\text { cannabis usage and knowledge on } \\
\text { cannabis-sedative drug interactions. The } \\
\text { correct answer is "no." } 14 \text { users said no } \\
\text { and } 2 \text { non-users said no. That is a } \\
\text { significant association in correct } \\
\text { responses. The users seem to be more } \\
\text { knowledgeable on this topic. }\end{array}$ \\
\hline $\begin{array}{l}\text { H06: Cannabis usage and knowledge } \\
\text { on possible adverse cannabis-cocaine } \\
\text { drug interactions is independent. } \\
\text { Ha6: Cannabis usage and knowledge } \\
\text { on possible adverse cannabis-cocaine } \\
\text { drug interactions is not independent. }\end{array}$ & $\mathrm{P}=0.47447$ & $\begin{array}{l}\text { Do not reject H06. } \\
\text { There is no association between } \\
\text { cannabis usage and knowledge on } \\
\text { cannabis-cocaine interactions. }\end{array}$ \\
\hline $\begin{array}{l}\text { H07: Cannabis usage and knowledge } \\
\text { on possible adverse cannabis-heroin } \\
\text { drug interactions is independent. } \\
\text { Ha7: Cannabis usage and knowledge } \\
\text { on possible adverse cannabis-heroin } \\
\text { drug interactions is not independent. }\end{array}$ & $\mathrm{P}=0.18618$ & $\begin{array}{l}\text { Do not reject } \mathrm{H} 07 . \\
\text { There is no association between } \\
\text { cannabis usage and knowledge on } \\
\text { cannabis-heroin interactions. }\end{array}$ \\
\hline
\end{tabular}

\section{Discussion}

The purpose of this study was to investigate associations between consumption of cannabis and knowledge of drug interactions between cannabis and various drugs. The study involved using a survey questionnaire to test knowledge on 
drug interactions among persons residing in the Vancouver, BC, area, specifically targeting those leaving dispensaries. A total of seven null hypotheses were tested based on different commonly used licit and illicit drugs; alcohol, blood thinner drugs, blood pressure drugs, opioid drugs, sedative drugs, cocaine, and heroin. Participants were placed in one of two study groups based on whether or not they consumed cannabis. Interestingly, both groups seemed to be knowledgeable only on the interaction of cannabis and alcohol, while for all the other drugs, they seemed to lack knowledge. However, only the interaction of cannabis with opioid drugs and sedative drugs were statistically significant

These findings agreed with previous research suggesting inadequate scientific knowledge regarding effectiveness, dosage, delivery mechanisms, indications and drug interactions in humans (Temple et al, 2018). This has a lot to do with legalization of cannabis being so recent. As such, it is expected that some of these gaps will be filled in, in the future. Many people argued that the government should have postponed legalization of cannabis until further research was conducted to ensure maximum safety of public. Had this been the case, physicians and pharmacists would have been able effectively communicate with patients who are already taking medications and thinking of using cannabis, or vice versa. Instead, Canadian healthcare plans do not cover the cost of medical cannabis, keeping it completely separate from the system, because of limited clinical studies (Dormer, 2018).

Healthcare specialist should be expected to safely prescribe or dispense cannabis just like any other controlled substance. Every day, there are new drugs on the market that physicians and pharmacist must keep up with. The different areas that they turn to for this information are guidelines, medical literature, organizations, continuing pharmacy education (CPE), and legislation, amongst many more (Schroeder, 2015). Once enough research is completed on the gray areas of cannabis, then it can also be treated like any other controlled substance, as part of our health care system. This will maximize the safety of the individuals who choose to consume this substance.

Another contribution that correlates with these findings is derived directly from the cannabis sales frontlines; the dispensary staff. There is a lack of educational standards for dispensary staff training (Clifton, 2018). Looking at the various job postings for cannabis retail jobs, the only requirements are that one is at least 19 years of age; rarely, one might require a high school diploma (Indeed, 2019). Another issue with dispensary staff relaying medical information to customers could lead to legal complications since they are not certified health care providers. This can greatly limit them from providing information to consumers in terms of drug interactions since they are simply not qualified to comment on this, even if they seem to be knowledgeable on the topic, because they can be held liable if something was to occur.

Lastly, another possible reason that these findings agree with previous research is because of the complexity and availability of dosing options for cannabis (Comeau, 2007). Modern day cultivation of cannabis has made the product that much more complex by giving rise to an infinite number of different strains. These strains are cultivated using different percentages of CBD and THC. Based on these percentages, along with other factors, cannabis is categorized as Indica, Sativa or Hybrid (Rahn, 2018). In conclusion, it is basically 
impossible to be an expert and to understand every strand of cannabis.

The results obtained from this study were as expected. The majority of people are knowledgeable on the interaction of cannabis and alcohol because there is something being done to educate and warn the public. This is evident in warning signage, television and radio commercials, as well as educational talks about alcohol that include sections about mixing with cannabis (Stigler et al, 2011). As for all the other drug interactions with cannabis, people are not knowledgeable at all. When comparing between cannabis users and nonusers, the alternate hypothesis was accepted only for opioid and sedative drugs. This most likely resulted due to chance, and does not change the fact that both the users and non-users were simply not educated at all on these commonly used drugs and their respective interaction outcomes with cannabis.

The main methodological limitations were time and small sample sizes. In turn, this caused the research to lack additional descriptive analysis (age, sex, residence, etc.). These results can be extrapolated to the entire general public. At some point in people's lives, they will depend on some type of medication to achieve a better quality of life. Knowing the outcome from mixing cannabis with commonly used licit and illicit drugs is crucial for the well being of these individuals, especially the elderly and immunocompromised. This is especially evident now that cannabis is legal in Canada and other parts of the world because people may choose to experiment for their first time, substitute other medications for cannabis, or simply use cannabis recreationally while already taking medications.

\section{Knowledge Translation and Recommendations}

The findings of this research paper clearly show us that the general public is uneducated when it comes to interactions between cannabis and licit and illicit drugs. The information gained from this research can be translated into any one of the different areas that physicians or pharmacist turn to in order to be kept up to date with information on new drugs and medications (as mentioned above). In addition to the drugs chosen for study subjects in this paper, other commonly and non-commonly used drugs should be studied for the outcome when interacting concurrently with cannabis. A large portion of the public depends on their health care professionals to relay this information to them. This is clearly evident between senior citizens and their pharmacist; seniors make up about 12 percent of the Canadian population and receive between 28 to 40 percent of all prescribed medication (Hospital News, 2019).

There are also ways to educate the younger and intermediate-aged population. Generally, elderly people will spend a lot of their time interacting with their physicians and pharmacists so they will have a higher chance of being informed about possible adverse interactions as a result of using cannabis concurrently with the medications they are already taking. However, younger individuals do not spend as much time interacting with health care professionals. The easiest and most convenient place to start educating the younger crowd could be in high school, similarly to the alcohol campaigns that the health authorities carry out. High school nurses should always be up to date with any new possible adverse reactions resulting from concurrently using cannabis and other drugs. In turn, these marijuana campaigns will encourage 
students to not consume cannabis if they are under 19, but if they do, then they can speak to the nurse in private to ensure that mixing cannabis with other drugs, that they may be be taking, does not lead to an adverse health reaction.

There are websites online that allow one to enter the names of the medications taken and it will show if there is a possibility of any adverse reactions occurring. A commonly used website is WebMD, which offers the interaction checker tool as seen in Figure 6 (WebMD, 2019).

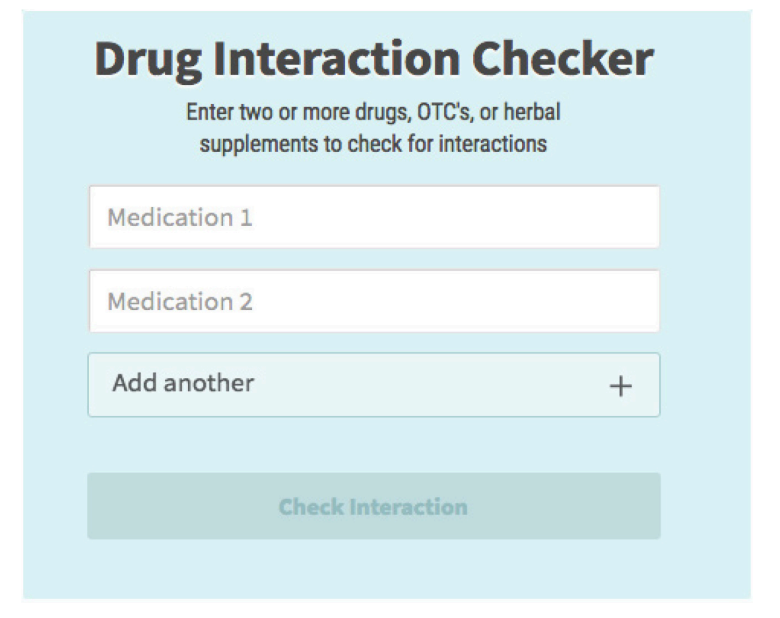

Figure 6. WebMD Interaction Checker (WebMD, 2019)

Cannabis should be incorporated into this system to allow people to include cannabis as one of the medications that they would like to check for adverse interactions. This paper does not support the act of selfdiagnosis via the Internet, but this could be very helpful in preventing adverse reactions from occurring. There should also always be a disclaimer instructing people to talk to their physician and/or pharmacist to confirm the search results.

\section{Limitations}

A normal limitation for research surveys tends to be time; this was also evident during this project. A large portion of time that could have been used to carry out the questionnaires was spent waiting on the approval from the BCIT Research Ethics Board to ensure that this research paper abided by all the ethical rules regarding inperson surveys. Had this time been available for distributing more surveys, this would have yielded more responses and thus would have improved the internal and external validity. An increase in completion of surveys would also have reduced beta error. Also, the lack of time led to constraints against carrying out additional descriptive analysis that would have resulted in more precise and accurate findings. To improve on these issues, a telephone survey could have been administered to save time. However, even though it might have saved some time, it also could have very likely resulted in a lower response rate as compared to in-person surveys.

Additionally, people tend to be more truthful in person as compared to over the phone or online, especially since cannabis has been legalized.

\section{Future Research}

A survey should be conducted to discover if the general public knows the different health effects of cannabis. Different health effects arise from different strains (Indica, Sativa, Hybrid) as well as the main compounds in the strain (THC, CBD). Additionally, a survey should be created for cannabis dispensers to conduct a knowledge test on various health aspects of cannabis. Lastly, a survey should be created for pharmacists to discover whether patients admit they are using cannabis during the preliminary questioning with the pharmacist, prior to receiving their medication. If so, how often does this happen? Additionally, how confident do the pharmacists feel giving advice on prescription use if someone is taking cannabis? 


\section{Conclusions}

Many people, especially as they get older, turn to medications, including cannabis, as a coping method to achieve a better quality of life. This is evident in Canada and other countries where cannabis has been legalized. Results from this study indicate that the general public is not very knowledgeable on the possible adverse reactions that may come about as a result of mixing cannabis and other commonly used licit and illicit drugs. In addition to the suggestions made in this paper to close this knowledge gap, the government should take action in providing the public and health professionals with tools that will aide them in making an informed decision about concurrently using cannabis and other licit and/or illicit drugs.

\section{Acknowledgements}

The authors thank the British Columbia Institute of Technology Environmental Health Department for supporting their research. Additionally, a special thank you to everyone who participated in the study.

\section{Competing Interest}

The authors declare they have no competing interest.

\section{References:}

1. Alshaarawy, O., \& Elbaz, H. A. (2016). Cannabis Use and Blood Pressure Levels: United States National Health and Nutrition Examination Survey, 2005-2012. Journal of Hypertension, 34(8), 1507-1512.

http://doi.org/10.1097/HJH.0000000 $\underline{000000990}$

2. Bakas, T., van Nieuwenhuijzen, P. S., Devenish, S. O., McGregor, I. S.,
Arnold, J. C., \& Chebib, M. (2017).

The direct actions of cannabidiol and 2-arachidonoyl glycerol at GABAAreceptors. Pharmacological Research. http://doi.org/10.1016/j.phrs.2017.02 .022

3. Bristol-Myers-Squibb. (2011). Warfarin Full Prescribing Information. FDA Drug Labeling, 136. Retrieved from http://www.accessdata.fda.gov/drugs atfda docs/label/2011/009218s1071b $\underline{1 . p d f}$

4. British Columbia Institute of Technology. (2018). Ethical Practice for Research Involving Human Participants (6500). British Columbia, Canada: British Columbia Institute of Technology

5. Cannabis Control and Licensing Act, (S.C. 2018), c. 17

6. Centers for Disease Control and Prevention. (2017). Prescription Opioids. $C d c$, (September), 1-12.

7. Clifton, M. (2018, November 05). Survey Finds Dispensary Staff Are Well Trained for Sales but Not for Medical Advice. Retrieved from https://www.greenentrepreneur.com/ $\underline{\operatorname{article} / 322629}$

8. Cooper, Z. D., Bedi, G., Ramesh, D., Balter, R., Comer, S. D., \& Haney, M. (2018). Impact of coadministration of oxycodone and smoked cannabis on analgesia and abuse liability. Neuropsychopharmacology. http://doi.org/10.1038/s41386-018$\underline{0011-2}$ 
9. Comeau, P. (2007). New dosage limits for medical marijuana: But wheres the science? Canadian Medical Association Journal, 177(6), 556-557. doi:10.1503/cmaj.071044

10. Degenhardt L., Hall W. (2012). Extent of Illicit Drug Use and Dependence, and their contribution to the Global Burden of Disease. Lancet. 379:55-70. DOI:10.1016/S0140-6736(11)61138$\underline{0}$

11. Dormer, D. (2018, August 04). Doctors want medical pot phased out after legalization: Canadian Medical Association | CBC News. Retrieved from https://www.cbc.ca/news/canada/cal gary/canadian-medical-associationcannabis-legalization-1.4772000

12. Evans, P. (2015, November 10). 31\% of Canadians would smoke pot if it were legal, poll suggests $\mid \mathrm{CBC}$ News. Retrieved from https://www.cbc.ca/news/business/m arijuana-pot-poll-survey-1.3312151

13. Foltin R. W., Fischman M. W., Pedroso J. J., Pearlson G. D. (1987). Marijuana and cocaine interactions in humans: cardiovascular consequences. Pharmacol Biochem Behav.28(4):459-464.

14. Grayson, L., Vines, B., Nichol, K., \& Szaflarski, J. P. (2018). An interaction between warfarin and cannabidiol, a case report. Epilepsy and Behavior Case Reports. http://doi.org/10.1016/j.ebcr.2017.10 .001
15. George Mason University. (2012).

Retrieved from https://ssac.gmu.edu/alcoholtobacco-and-other-drugs/uppersdowners-and-all-arounders/

16. Greater Vancouver Cannabis Dispensaries. (2018). Retrieved from https://www.straight.com/cannabis/g reater-vancouver-cannabisdispensaries

17. Google Maps. (2018). Retrieved from https://goo.gl/maps/iZPqx96efKm

18. Hartman, R. L., Brown, T. L., Milavetz, G., Spurgin, A., Gorelick, D. A., Gaffney, G., Huestis, M. A. (2015). Controlled cannabis vaporizer administration: Blood and plasma cannabinoids with and without alcohol. Clinical Chemistry. http://doi.org/10.1373/clinchem.2015 .238287

19. Heacock, H. (n.d.). Research Methods ENVH 8400, Module 2 [PowerPoint slides]. Retrieved from https://learn.bcit.ca/d21/le/content $/ 48$ $\underline{3396 / \text { viewContent/3223479/View }}$

20. Heacock, H. (n.d.). Research Methods ENVH 8400, Module 3 [PowerPoint slides]. Retrieved from https://learn.bcit.ca/d21/le/content/48 3396/viewContent/3223484/View

21. Hillmer, B. (2017, January 24). Best Practices: Understanding and Reducing Bias in Your Surveys. Retrieved from 
https://help.surveygizmo.com/help/s urvey-bias

22. Hospital News. (2019, January 18). The role of the pharmacist in senior care. Retrieved from https://hospitalnews.com/the-role-ofthe-pharmacist-in-senior-care/

23. Indeed. (2019). Cannabis Jobs. Retrieved from https://ca.indeed.com/Cannabisjobs?advn=2083459076665214\&vjk $=7 \mathrm{db} 53406 \mathrm{~d} 36 \mathrm{eb} 3 \mathrm{f} 2$

24. INR Test Explained. (2017, November 24). INR Test. Retrieved from https://healthengine.com.au/info/INR $\underline{\text {-Test }}$

25. Internal Consistency Reliability: Definition, Examples. (2018, June 17). Retrieved from https://www.statisticshowto.datascie ncecentral.com/internal-consistency/

26. In-Person Surveys vs. Online Surveys. (2018, August 09). Retrieved from http://mmrstrategy.com/are-inperson-surveys-better-than-online$\underline{\text { surveys/ }}$

27. Izzo, JL, Levy, D, \& Black, H.R. (2000). Importance of Systolic Blood Pressure in Older Americans. Hypertension. 35. 10.1161/01.HYP.35.5.1021.

28. Kaplan, J. (2018, February 25). Cannabis' Effects on the Heart. Retrieved from https://neurokaplan.com/2018/02/25/ cannabis-effects-on-the-heart/
29. Lindsay J. A,. Slotts A. L., Green C. E., Herin D. V., Schmitz J. M. (2009). Cocaine Dependence and Concurrent Marijuana Use: A Comparison of Clinical Characteristics. AM J Drug Alcohol Abuse.35(3):193-198. doi: $\underline{10.1080 / 00952990902933860}$

30. Livingston, M. D., Barnett, T. E., Delcher, C., \& Wagenaar, A. C. (2017). Recreational Cannabis Legalization and Opioid-Related Deaths in Colorado, 2000-2015. Am J Public Health. 107(11): 18271829. http://komornlaw.com/wpcontent/uploads/2018/01/livingston2 $\underline{017 . p d f}$

31. Millar, J.A., \& Lever A.F. (2000). Implications of Pulse Pressure as a Predictor of Cardiac Risk in Patients With Hypertension. Hypertension. 36. 907-11. 10.1161/01.HYP.36.5.907.

32. Mora, M. (2016, October 19). Validity and Reliability in Surveys. Retrieved from https://www.relevantinsights.com/bl og/validity-and-reliability

33. Oliveira, R., Johnstone, S., \& Chen, P. (2017, April 19). Discovery that cannabidiol acts over GABA neurons could explain its antiepileptic properties. Retrieved from https://news.lift.co/discoverycannabidiol-acts-gaba-neuronsexplain-antiepileptic-properties/

34. Pacher, P., Bátkai, S., \& Kunos, G. (2005). Blood pressure regulation by endocannabinoids and their receptors. Neuropharmacology. 
http://doi.org/10.1016/j.neuropharm. $\underline{2004.12 .005}$

35. Rahn, B. (2018, November 16). Indica vs. Sativa Cannabis Strains: Which Produces More THC or CBD? Retrieved from https://www.leafly.com/news/cannab is-101/indica-vs-sativa-whichproduces-more-cbd-thc

36. Ren, Y., Whittard, J., HigueraMatas, A., Morris, C. V., \& Hurd, Y. L. (2009). Cannabidiol, a Nonpsychotropic Component of Cannabis, Inhibits Cue-Induced Heroin Seeking and Normalizes Discrete Mesolimbic Neuronal Disturbances. Journal of Neuroscience. https://doi.org/10.1523/JNEUROSCI .4291-09.2009

37. Royal Queen Seeds. (2017, May 15). How cannabis interacts with other drugs. Retrieved from https://www.royalqueenseeds.com/bl og-how-cannabis-interacts-withother-drugs-n502

38. Scavone, J. L., Sterling, R. C., Weinstein, S. P., \& Van Bockstaele, E. J. (2013). Impact of cannabis use during stabilization on methadone maintenance treatment. American Journal on Addictions. https://doi.org/10.1111/j.1521$\underline{0391.2013 .12044 . \mathrm{x}}$

39. Schwilke, E. W., Schwope, D. M., Karschner, E. L., Lowe, R. H., Darwin, W. D., Kelly, D. L., ... Huestis, M. A. (2009). $\Delta 9$ tetrahydrocannabinol (THC), 11hydroxy-THC, and 11-nor-9carboxy-THC plasma pharmacokinetics during and after continuous high-dose oral THC. Clinical Chemistry. http://doi.org/10.1373/clinchem.2008 $\underline{.122119}$

40. Schroeder, M. N. (2015, January 22). Staying up-to-date as a new practitioner. Retrieved from https://www.pharmacist.com/article/s taying-date-new-practitioner

41. Statista (2018). Marijuana consumption Canada 2017 | Statistic. Retrieved from https://www.statista.com/statistics/58 7689/marijuana-consumptioncanada/

42. Statistics Canada (2017). High blood pressure, by age group. Retrieved from https://www150.statcan.gc.ca/t1/tbl1/ en/tv.action?pid=1310009609

43. Statistics Canada (2016). Blood pressure of adults, 2012 - 2015. Retrieved from https://www150.statcan.gc.ca/n1/pub /82-625-x/2016001/article/14657eng.htm

44. Statistics. Canada. (2017, October 10). Adverse Reaction and Medical Device Reporting. Retrieved from https://www.canada.ca/en/healthcanada/services/drugs-healthproducts/medeffect-canada/adversereaction-reporting.html\#a3

45. Stigler, M. H., Neusel, E., \& Perry, C. L. (2011). School-based programs to prevent and reduce alcohol use among youth. Alcohol research \& health : the journal of the National Institute on Alcohol Abuse and 
Alcoholism, 34(2), 157-62.

46. Temple, L. M., Lampert, S. L., \&

Ewigman, B. (2019). Barriers to Achieving Optimal Success with Medical Cannabis: Opportunities for Quality Improvement. The Journal of Alternative and Complementary Medicine, 25(1), 5-7. doi:10.1089/acm.2018.0250

47. The Recovery Village (2018). Cocaine and Weed: Can You Mix Weed and Cocaine? Retrieved from https://www.therecoveryvillage.com/ cocaine-addiction/cocaine-andweed/\#gref

48. The Journal. (2015, October 25). The potent mixture of marijuana and heroin that's destroying South Africa's youth. Retrieved from http://www.thejournal.ie/nyaope2408072-Oct2015/

49. WebMD. (2019). Drug Interaction Checker - Find Interactions Between Medications. Retrieved from https:/www.webmd.com/interactionchecker/default.htm

50. Williams, B., Lindholm, L. H., \& Sever, P. (2008). Systolic pressure is all that matters. The Lancet. http://doi.org/10.1016/S0140$\underline{6736(08) 60804-1}$

51. World Drug Report 2018. Report no. E.18.XI.9, United Nations Office on Drugs and Crime, Vienna, Austria 2018. https://www.unodc.org/wdr2018/prel aunch/WDR18 Booklet 3 DRUG MARKETS.pdf 